\title{
Paulo Freire, 100 anos de ideias e ideais. Registros impressos e reflexões sobre a comunicação e a ética do Patrono da Educação Brasileira
}

\author{
Paulo Freire, 100 years of ideas and ideals. Printed records and reflections on \\ communication and ethics of the Patron of Brazilian Education
}

Paulo Freire, 100 años de ideas e ideales. Actas impresas y reflexiones sobre comunicación y ética del Patrón de la Educación Brasileña

Pedro Serico Vaz Filho

<pedrovaz@uol.com.br>

\section{Resumo}

0 presente artigo enfatiza a trajetória do educador pernambucano Paulo Freire, sobre o método de alfabetização criado por ele que teve êxitos e repercussões nacionais e internacionais. Da mesma forma retrata o caráter político, social e ético desse autor com mais de trinta obras traduzidas em diversos idiomas. Ele, que recebeu inúmeras homenagens e títulos no Brasil em diversos países, completaria 100 anos de idade em 19 de setembro de 2021. Entre as fontes de consulta para 0 desenvolvimento desta pesquisa consta o jornal Diario de PernambuCo, com sede na cidade de Recife. 0 citado periódico registrou fases fundamentais das ações de Freire, considerado um dos maiores pensadores da nossa história. Este trabalho conta ainda com referências renomadas como os professores André Barbosa Filho, Celso de Rui Beisiegel, Sérgio Haddad e Venício Artur de Lima.

Palavras-chave: Paulo Freire. Alfabetização. Educação. Ética. Diario de Pernambuco.

\section{Abstract}

The present article emphasizes the trajectory of the educator Paulo Freire, about the literacy method he created, which had national and international success and repercussions. It also portrays the political, social and ethical character of this author, whose more than thirty works have been translated into several languages. He received countless tributes and titles in Brazil and in several other countries. He would be 100 years old on September 19, 2021. Among the sources of consultation for the development of this research is the newspaper Diario de Pernambuco, based in the city of Recife. This newspaper has registered fundamental phases of Freire's actions, who is considered one of the greatest thinkers in our history. This work also counts on renowned references such as professors André Barbosa Filho, Celso de Rui Beisiegel, Sérgio Haddad, and Venício Artur de Lima.

Keywords: Paulo Freire. Literacy. Education. Ethical. Diario de Pernambuco.

\section{Resumen}

El presente artículo destaca la trayectoria del educador pernambucano Paulo Freire, sobre el método de alfabetización que creó, que tuvo éxito y repercusión nacional e internacional. También retrata el carácter político, social y ético de este autor con más de treinta obras traducidas a varios idiomas. Recibió numerosos honores y títulos en Brasil y varios países, cumpliría 100 años de edad el 19 de septiembre de 2021. Entre las fuentes de consulta para el desarrollo de esta investigación está el periódico Diario de Pernambuco, con sede en la ciudad de Recife. Este periódico, registró fases clave de la acción de Freire, considerado uno de los mayores pensadores de nuestra historia. Esta obra cuenta también con referencias de renombre como los profesores André Barbosa Filho, Celso de Rui Beisiegel, Sérgio Haddad y Venício Lima.

Palabras clave: Paulo Freire, Alfabetización. Educación. Ético. Diario de Pernambuco. 
O ano de 2021, registra o centenário de Paulo Reglus Neves Freire, nascido no dia 19 de setembro de 1921, em Recife, Pernambuco. Com formação em Direito, foi também filósofo, sociólogo, escritor e professor universitário. Paulo Freire, abreviação do nome, torna-se assim conhecido mundialmente pelas dezenas de obras que escreveu, com traduções em diversos países. O livro Pedagogia do Oprimido, de 1968, assinado por ele destaca-se entre os mais importantes nas áreas da educação e pedagogia. Freire conquistou 35 títulos Honoris Causa em universidades do Brasil e do exterior. No ano de 2012, a Lei n. 12.612, declara Paulo Freire Patrono da Educação Brasileira. Em 2 de maio de 1997, morre aos 75 anos de idade, em São Paulo, após sofrer um ataque cardíaco.

Freire era filho do capitão da polícia militar, Joaquim Temistocles Freire e de Deltrudes Neves Freire, conhecida como dona Tudinha. A família de classe média sofre os abalos financeiros com a quebra da bolsa de valores de Nova York, em 1929. A contração econômica impõe que Freire, os pais, a irmã Stela e os dois irmãos, Armando e Temistocles, deixem Recife. Eles passam a morar em Jaboatão dos Guararapes, cidade vizinha, que oferecia menor custo de vida. A morte do pai em 1934, quando ele tinha 13 anos de idade, agrava situação causando restrições na alimentação e na educação.

Paulo Freire foi alfabetizado em casa pelos pais. Em 1927, aos seis anos de idade sabia ler e escrever. Concluiu o ensino primário no Colégio 14 de Julho, em Recife. A fase seguinte foi através de uma bolsa de estudos conseguida pela mãe no Colégio Oswaldo Cruz, na capital pernambucana, em 1937, quando tinha 15 anos. A influência da mãe foi marcante na vida de Freire, bem como da primeira esposa, Elza Maria Costa Oliveira, com quem se casou em 1944 e teve cinco filhos - na ordem: Maria Madalena, Maria Cristina, Maria de Fátima, Joaquim e Lutgardes. Viúvo de Elza, em 1986, Freire casou-se novamente em 1988 com a ex-aluna Ana Maria Araújo.

Freire tinha vinte e três anos quando se casou com uma professora primária, igualmente católica. À época, ele já trabalhava como professor do curso secundário, mas foi graças à influência de sua mulher que Freire começou a estudar o problema da educação de forma mais sistemática. Seus interesses se concentraram na filosofia e sociologia da educação. (LIMA, 1981, p. 23).

A desigualdade social inquietava Paulo Freire já na infância e na adolescência. $\mathrm{O}$ empobrecimento da família marca a personalidade do menino. As mudanças da urbanidade de Recife para o ambiente rural de Jaboatão dos Guararapes geram elementos marcantes e objetos de estudos para o educador.

A educação é também um ato político. A ideologia dominante "vive" dentro de nós e também definitiva, nunca poderíamos pensar na transformação social. Mas a transformação é possível porque a consciência não é um espelho do simples reflexo, mas é reflexiva e refletora da realidade. Enquanto seres humanos conscientes, podemos descobrir como somos condicionados pela ideologia dominante. Podemos distanciar da nossa época podemos aprender, portanto, como nos libertar através da luta política na sociedade. 
Podemos lutar para ser livres, precisamente por que sabemos que não somos livres? É por isso que podemos pensar na transformação. (FREIRE, 1986, p. 17).

No final da década de 1920 e no decênio de 1930, o estudioso Paulo Freire vivia atento à situação de adultos e idosos em situação iletrada. No Brasil, o número de analfabetos naquele período ultrapassava a marca de $60 \%$ da população. ${ }^{1}$ Freire se espantava por estar na condição de minoria alfabetizada, entre a maioria sem formação escolar.

Os analfabetos sabem que são seres concretos. Sabem que fazem coisas. Mas o que às vezes não sabem, na cultura do silêncio, em que se tornam ambíguos e duais, é que sua ação transformadora, como tal os caracteriza como seres criadores e recriadores. Submetidos aos mitos da cultura dominante, entre eles o de sua "natural inferioridade", não percebem, quase sempre, a significação real de sua ação transformadora sobre o mundo. Dificultados em reconhecer a razão de ser dos fatos que os envolvem, é natural que muitos, entre eles, não estabeleçam a relação entre não "ter voz", não "dizer a palavra", e o sistema de exploração em que vivem. (FREIRE, 1982, p. 49-50).

Pelas referências sobre o educador entende-se que a base do pensamento de
Freire está moldada pelos estudos sociais e vivência nordestina, de onde se insurge e defende questões éticas em frases como: "Quando, porém, falo da ética universal do ser humano estou falando da ética enquanto marca da natureza humana, enquanto algo absolutamente indispensável à convivência humana" (FREIRE, 1996, p. 9). Pela atuação profissional e intelectual, Paulo Freire, aos 25 anos de idade, em 1946, passa a ocupar o cargo de diretor do Departamento de Educação e Cultura do Serviço Social de Pernambuco, fase do início do trabalho dele com analfabetos adultos.

Após uma primeira experiência profissional como professor de português no próprio Colégio Oswaldo Cruz, foi designado, em 1947, para a diretoria do setor de Educação e Cultura do Sesi de Pernambuco. Em 1954 assumiu a superintendência da instituição, aí permanecendo até 1957. Lecionou filosofia da educação na Escola de Serviço Social do Recife. Em 1959, concorreu ao provimento da cadeira de história e filosofia da educação da antiga Escola de Belas Artes de Pernambuco. Não foi indicado, mas o título de doutor obtido pela participação no concurso possibilitou-lhe, em 1960, a nomeação para o cargo de professor efetivo de filosofia e história da educação da Faculdade de Filosofia, Ciências e Letras da Universidade do Recife. (BEISIEGEL, 2010, p. 14). ${ }^{2}$

\footnotetext{
$1 \mathrm{~A}$ partir do século XIX, o percentual de analfabetismo (considerando como analfabeto o que não sabe ler e escrever; ou seja, no sentido censitário tradicional), começou a cair no Brasil. No entanto, até 1920, 0 índice de analfabetismo ainda superava 2/3 de sua população, o que equivalia a 64,9\% das pessoas acima de quinze anos (BORTONI-RICARDO; SILVA; CAXANGÁ; LINS, p. 217). Na década de 1930 não houve censo. As alegações eram de ordem política, como a Revolução de 1930.

2 Disponivel em: http://www.dominiopublico.gov.br/download/texto/me4713.pdf. Acesso em: 20 fev. 2021.
} 
Formado em Direito, em 1946, Freire desiste da carreira de advogado e se dedica aos estudos de Pedagogia, Sociologia e Filosofia. Os textos em capas, abas e orelhas de livros elencam histórias, exaltações e diferenciais desse brasileiro, que está entre os intelectuais mais conhecidos do mundo:

O método Paulo Freire é de educação de adultos, não de alfabetização de adultos, porque Paulo Freire, visa antes de mais nada, ensinar a estudar - o que, para ele, significa repensar e não armazenar ideias alheias: significa assumir uma atitude crítica diante do que se estuda e estendê-la à realidade social, à sua própria existência e à visão do mundo. Para Paulo Freire, alfabetizar não é apenas ensinar um léxico, aprender a pronunciar e escrever palavras. "Escrita e lida" - diz Paulo Freire - "a palavra é como se fosse um amuleto, algo justaposto ao homem que não a diz, mas simplesmente a repete. Palavra quase sempre sem relação com o mundo e com as coisas que nomeia." O papel de Paulo Freire como educador, filósofo da educação e humanista é hoje reconhecido no mundo inteiro. Pode-se mesmo afirmar que entre os intelectuais brasileiros mais conhecidos e conceituados nos círculos cultos de todo o mundo, está o nome de Paulo Freire, ao lado de Oscar Niemeyer e Celso Furtado. ${ }^{3}$

Os projetos educacionais de Freire se desenvolvem nos anos de 1940 e na década de 1950. Porém, a notoriedade em pági- nas de jornais se dará a partir da década de 1960. Nesse decênio, ultrapassa as divisas de Pernambuco, pelos êxitos obtidos no campo da alfabetização.

Em maio de 1960, participou do início do Movimento de Cultura Popular (MCP) do Recife, um importante movimento cultural criado pelo prefeito Miguel Arraes e organizado sob a orientação e a liderança de Germano Coelho. Paulo Freire assumiu a direção da Divisão de Pesquisas da entidade. Em fevereiro de 1962, assumiu a direção do recém-criado Serviço de Extensão Cultural (SEG) da Universidade do Recife. Em meados de 1963, foi designado pelo ministro Paulo de Tarso para a presidência da recém-criada Comissão Nacional de Cultura Popular e, em março do ano seguinte, assumiu a coordenação do Programa Nacional de Alfabetização, então promovido pelo Ministério da Educação com a utilização do método Paulo Freire de alfabetização de adultos. Esses primeiros tempos de atuação do educador foram marcados por seus trabalhos na educação de adultos analfabetos. Não obstante o amplo elenco de atividades que viera desenvolvendo, Paulo Freire só começou a tornar-se conhecido no Brasil no início de 1963, quando o seu método de alfabetização de adultos foi divulgado em ampla campanha publicitária promovida pela Secretaria de Educação do Estado do Rio Grande do Norte. O governo do estado empregara o mé-

3 Texto publicado na quarta capa do livro Ação Cultural Para a Liberdade e outros escritos, assinado por Paulo Freire, pela editora Paz e Terra. Edição de 1984. 
todo de Paulo Freire no movimento de educação de adultos analfabetos, então iniciado na experiência-piloto realizada em Angicos, cidade natal do governador Aluízio Alves. Num primeiro momento, divulgou-se que o governo do estado realizava uma campanha de educação com um novo método, que alfabetizava jovens e adultos em quarenta horas. (BEISIEGEL, 2010, p. 14). ${ }^{4}$

O nome de Paulo Freire se vincula à lista de ilustres personagens e feitos orgulhosos de Pernambuco. Entre estes: a criação do Diario de Pernambuco, ${ }^{5}$ o mais antigo jornal da América Latina, fundado em 7 de novembro de 1825, em Recife, bem como a fundação da Rádio Clube de Pernambuco, em 6 de abril de 1919, primeira estação do rádio do país e da América Latina. A graduação de Freire em Direito foi iniciada quando ele tinha 21 anos de idade, na $\mathrm{Fa}$ culdade de Direito de Recife (atualmente Universidade Federal de Pernambuco). Foi a primeira instituição de ensino superior do Brasil, fundada em 11 de agosto de 1827, na mesma data que a Faculdade de Direito da Universidade de São Paulo.

Já na juventude, suas leituras incluíam pensadores católicos, tais como Tristão de Athayde, o novelista francês George Bernanos, que morou no Brasil de 1938 a 1945, e Emanuel Mounier. Na verdade, Freire jamais negou seu cristianismo. Muito pelo contrário afirmou-o em diversas ocasiões. Uma de suas declarações mais eloquentes foi feita em Roma, em 1971 [...]: O cristianismo é, para mim, uma doutrina maravilhosa. Algumas pessoas já me acusaram de ser comunista, porém, nenhum comunista seria capaz de dizer o que acabei de dizer. A razão disto é que eu ainda não sou um católico completo, mas continuo tentando sê-lo mais integralmente, dia após dia. A condição de ser é continuar a ser. Nunca senti que precisaria abandonar a Igreja ou pôr de lado minhas convicções cristãs para poder dizer o que digo, ou ir para a prisão - ou, mesmo recusar-me a fazê-lo. Apenas sinto, apaixonadamente intimamente, organicamente, com todas as forças do meu ser, que a minha posição é a de um cristão, pois ela é 100 por cento revolucionária, humana e libertadora e, portanto, engajada e utópica. (LIMA, 1981, p. 22-23).

Paulo Freire, considerado um dos maiores pensadores do século XX, impressionava pela simplicidade quando se referia a ele mesmo.

Gosto de ser homem, de ser gente, porque não está dado como certo, inequívoco, irrevogável que sou ou serei decente, que testemunharei sempre gestos puros, sou ou serei justo, que respeitarei os outros, que não mentirei escondendo o seu valor porque a inveja de sua presença no mundo incomoda e me enraivece. Gosto de ser homem, de ser gente, porque sei que a minha passagem pelo mundo não é predeterminada, preestabelecida. Que 
o meu "destino" não é um dado, mas algo que precisa ser feito e de cuja responsabilidade não posso me eximir. (FREIRE, 1996, p. 59).

O escritor Sergio Haddad, professor e doutor em história e filosofia da educação da Universidade de São Paulo, no livro O Educador: Um perfil de Paulo Freire, de 2019, explora com detalhes as experiências e referências sobre a prisão e exílio do professor pernambucano, a partir do golpe militar de $1964 .{ }^{6}$ Os estudos do autor são aprofundados com fatores inéditos. A publicação é ainda de importante esclarecimento sobre o marco da alfabetização nacional para trezentos adultos em 45 dias, ocorrido na cidade de Angicos, Rio Grande do Norte, em 1963, pelo método Paulo Freire.

Quanto à indicação de Angicos para sediar o programa, a dificuldade dizia respeito a conflitos de natureza regional. Berço político do governador Aluízio Alves, a escolha da cidade no interior tinha claro objetivo de reforçar suas bases eleitorais; assim, Alves poderia fazer frente à bem-sucedida experiência encampada pelo adversário Djalma Maranhão em Natal, também apoiada pelo SEC. Para neutralizar a possível exploração política de seu programa, Paulo tentou restringir ao máximo as visitas de representantes partidários aos Círculos de Cultura em funcionamento - o que se mostraria quase impossível diante do clima de polarização. A equipe do SEC iniciou a formação dos estudantes em dezembro de 1962. Apresentaram-se para o trabalho em Angicos não apenas alunos de pedagogia, mas também lideranças estudantis de outros cursos interessados em participar das ações de alfabetização naquele contexto de mobilização política. (HADDAD, 2019, p. 777).

Além de enfatizar as questões políticas do contexto de 1963 em Angicos, Haddad revela detalhes sobre os anseios dos participantes e a organização do programa de alfabetização de Paulo Freire naquela cidade.

Angicos se agitava com a expectativa do início dos trabalhos. Filhos estimulavam os pais, amigos e parentes incentivavam uns aos outros para que superassem a resistência e participassem do projeto. Além dos locais públicos, muitas famílias cederiam espaços próprios para montar salas de aulas. Cadeiras improvisadas chegavam carregadas pelos alunos, que as levavam de volta ao término das aulas. O clima era positivo e estimulante. Entre os matriculados, 66 disseram que a motivação para participar do programa era melhorar de vida; 26 queriam ser motoristas; 23 , ler os jornais; vinte, ser professores; vinte moças almejavam ser costureiras; dezoito inscritos indicaram que tinham a intenção de "saber mais"; dezessete queriam escrever cartas para amigos e parentes; quinze, ajudar os outros; onze, ser comerciantes; dez, vo- 
tar; quatro trabalhar com música; e outros quatro queriam poder ler a Bíblia. (HADDAD, 2019, p. 806).

A vivência de Freire, em depoimentos no livro Medo e ousadia, o cotidiano do professor, obra conjunta do educador com a professora Ira Shor, descreve a emoção do trabalho que ele realizou em 1963, com universitários e trabalhadores rurais analfabetos.

O momento era extraordinário. Os jovens estavam absolutamente motivados historicamente para participar da transformação. Lembro-me de que, uma vez, precisávamos de 600 estudantes para trabalhar como professores na alfabetização de adultos numa área do Rio de Janeiro. Pusemos um anúncio no jornal e apareceram 6.000 candidatos! (Ira ri.) Foi terrível! Tivemos que entrevistá-los num estádio para selecionar os 600 , em fins de 1963. Foi um tempo de fantástica mobilização popular, e a educação fazia parte dela, era um de seus elementos principais, até que veio o Golpe. (FREIRE; SHOR, 1986, p. 94).

Quando o Método Paulo Freire passa a fazer parte da política de desenvolvimento do governo do presidente João Goulart (1961-1964), o educador torna-se personalidade positivamente pautada nos jornais brasileiros. Ele conquistava a simpatia, a admiração e o reconhecimento pelo trabalho que realizava. "Pelas características e pela qualidade de suas propostas, surgiu como o personagem mais conhecido no processo de envolvimento da educação de adultos analfabetos nas tensões políticas e ideológicas que agitaram essa etapa de nossa história” (BEISIEGEL, 2010, p. 15).

O escritor e sociólogo Venício Artur de Lima, na obra Comunicação e Cultura: as ideias de Paulo Freire, de 1981, declara que o educador não recebia "a devida atenção por parte de estudiosos da comunicação" (LIMA, 1981, p. 169), oposto aos profissionais e estudiosos das áreas da educação e pedagogia, os quais, nos anos 1960 passam a exaltar o método de Paulo Freire, o que é elucidado por Lima sobre o contexto das mudanças no Brasil, sobretudo em relação ao processo que leva Freire à prisão e ao exílio em 1964. O autor explora também o trabalho do professor com a abertura política, que seguia pelo então governo do presidente da República, o general João Batista de Oliveira Figueiredo (1979-1985).

Após o sucesso alcançado por suas experiências no Nordeste, Freire foi convidado pelo Ministério da Educação, em junho de 1963, a coordenar um grupo de trabalho encarregado de elaborar um plano nacional de educação de adultos. Freire trabalhou em Brasília até março de 1964, mas o plano, que chegou a ser aprovado e transformado em lei em janeiro, nunca foi posto em prática. Freire e seu método foram considerados subversivos e atentatórios à segurança nacional pelos militares que tomaram o poder após o golpe de $1^{\circ}$ de abril de 1964 . (LIMA, 1981, p. 22-23).

Dos meios impressos da época do início do método de Paulo Freire, o nome do educador era constante no jornal Diario 


\section{Cariocas E Paraibanos Aprendem No}

\section{Recife A Formar Alfabetizadores}

Vinte e dois univeraitarios da as cquips, riograndense parai- fconomico, o social. o politico Puntifica Universidade Catolica bana e recifense,

do Rio cie Janeiro e mais cinquerita paraibanos injeiaram, curso ministrado pelo ral da Universidade do Recife e servico de Fxtensio Cultural um orzkio criado no ano passa. da Unifersidade do Recife, de do e cujo prineipal objetivo e formacto de alfabclizadores, a- levar a Universidade a agir jun traves do método do profescor to ao povo, alem de leva-la a Paulo Freire, cuja primeira ex- rurticipor de modo man am. puriencia foi realizada no Rio plo e efetivo so caforco de soGrande do Norte e encerrada c'guimento tegional cin que so com a presenca do presidente caijenha, pesencmente o Nor. da Itepublice.

dexte:

Alem dos catudanies do Rio e ca Paraba, frequentarôno

Dentro dèsse objetivo e de outras metas. cono spomover e o cultural e estudo de suas tendencias ideologicas.

b) BDUCACXO BRABILETRA - estudo da educaço do Brasil como pais menos desenvolvido, suas deficiencias e ceteitos quantitativos e qualificativos, alem de uma snalise critica dos documentos que defincm a politica dos governos bara a educacbo. $\mathbf{O}$ curso ainda abranze estudo sobre a universidade brasileira além de seminarios sobre as diretrizes para uma politica educacional.

OnMETIVOS

Figura 1 - Matéria publicada no Diario de Pernambuco, 14 abr. 1963, p. 11.

de Pernambuco, o que possibilita remontar referências da vida do professor, incluindo sua prisão em 1964, o exílio e o retorno ao Brasil, em 1979, com a abertura política. Também os lançamentos de livros, as homenagens; o ingresso como secretário de Educação na prefeitura de São Paulo (1989-1991), na gestão da prefeita Luiza Erundina, ao falecimento em 1997, além de menções póstumas.

A reprodução do Diario de Pernambuco, de 14 de abril de 1963, registra a formação de universitários em curso de capacitação de alfabetizadores pelo método Paulo Freire (Figura 1). Outras inserções no jornal daquele ano servem como amostragem de publicações, que reafirmam a motivação de estudantes para o ensino de adultos analfabetos. Entre elas estão uma matéria de 25 de abril de 1963 (p. 9), sob o título "Estudantes de Goiás farão curso no Recife" e um artigo publicado em 29 de maio de 1963 (p. 5), com o título "Preparação de Alfabetizadores em Natal".

As divulgações seguiam constantes no Diario de Pernambuco, com títulos elogiosos ao trabalho de Paulo Freire. Revelavam os êxitos das aulas com trabalhadores analfabetos de salinas, de plantações de algodão, entre outros camponeses.

Na edição de 21 de junho de 1963, a primeira página do jornal, destaca: "Programa educacional da Aliança em Angicos obtém franco sucesso" (Figura 2). Dois dias depois, em 23 junho de 1963, na página 8 do jornal, outro título impactante: "Analfabeta chorou em Angicos ao escrever a primeira palavra" (Figura 3). 


\section{Programa educacional da "Aliança" em Angicos obtém franco sucesso}

Uin prezrama concrimcetat de proporcionadas nela nesocica. aliaketiracio de afultos citi ucn. Antos da experioncia de AngiCo cxosutado sm Anzicos, so Kio cos, e rrodevies Paulo Freire dey Grande do Xorie, sob os avei. um carso de ireinamemo a is

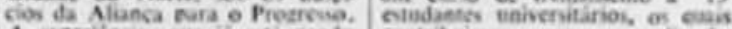

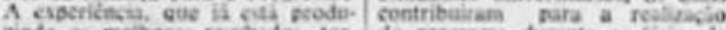

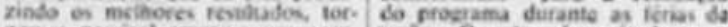

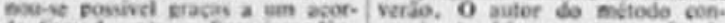

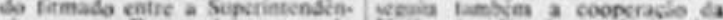

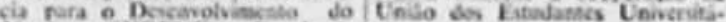

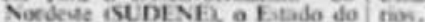

Rie Grande do Nortis, e Minis Ov rusuludos do frearama, eue Krio da Eibacac5ios e a Akcncia tere inicio em fanciro Seste and

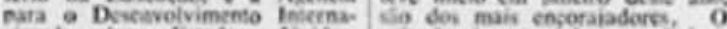
ciosal Jos Evabos Ueidos (L) MD).

A coniribuicio da USAID pura cuse trostami experitscetal goe. sivis cni uma wobvensto de 100 miabler de srurcitos do Euado to Rig Grimble do Norts, empriss timo de cquipumento judio-vineal don para " no kn clasiss. A cor everation do Smilo de Pouca. cho do Rio Grable do Norte (StCIRV), fornccer veiculion. combustivet, coliticasucs e dchesis melowo e cucksalmente Aalmi: ca. comereendendo dramatimacoles.

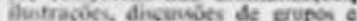
cnvito dircto, $O$ prosesio vea sendo aplicabo ch Anebon. com alnamas lieciras rovisbss 36 . ra cutcndilo a bodo o Fusado e a eutras resiuses do Nordeste. Ne. wos surves do kincro, por exito lado. in coincciram a scr orga. nivatos cen Natal e no Eusdo de Putrasaboco.

POHTA EM VTVTE DIA

Para \& ter umx" Melia da cficl.

Figura 2 - Inserção na primeira página do jornal Diario de Pernambuco, 21 jun. 1963.

\begin{tabular}{|c|c|c|}
\hline 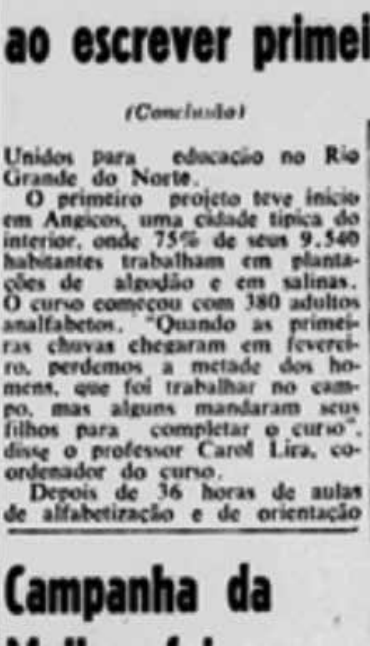 & 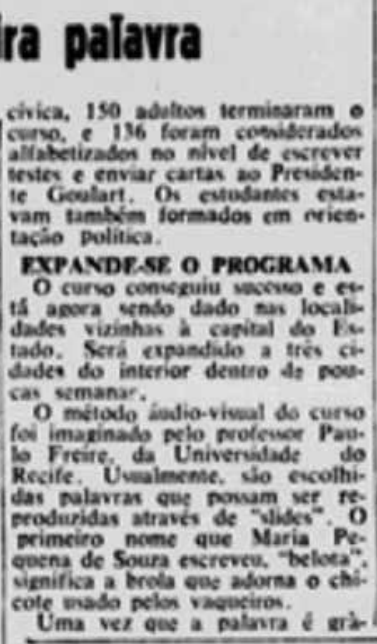 & 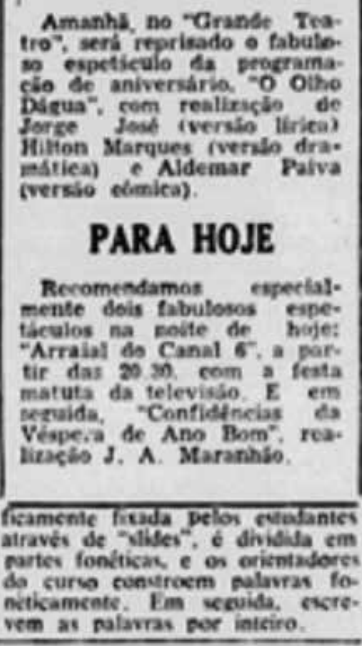 \\
\hline
\end{tabular}

Figura 3 - Inserção publicada no Diario de Pernambuco, 23 jun. 1963, p. 8. 
Inicialmente, nas aulas eram aproveitados os conhecimentos gerais dos alunos para posteriormente seguirem com o trabalho de alfabetização. O método de ensino foi dividido em etapas:

A primeira consistiu no trabalho de identificação do vocabulário usado pelos habitantes de Angicos e coletas de dados sobre suas condições econômicas e sociais. Em seguida, os adultos passaram a ser recrutados para os cursos. Finalmente os cursos tiveram início, baseados nas informações pelas pesquisas. Antes da experiência de Angicos, o professor Paulo Freire deu um curso de treinamento a 15 estudantes universitários, os quais contribuíram para a realização do programa durante as férias de verão. $\mathrm{O}$ autor do método conseguiu também a cooperação da União de Estudantes Universitários. ${ }^{7}$

Até o início de 1964, os trabalhos de Paulo Freire eram divulgados no Diario de Pernambuco e demais jornais e revistas, com ênfase na excelência do método de alfabetização por ele desenvolvido. Porém, a pressão política contrária ao pensador se intensificava, assim como os inimigos. Considerado subversivo pelo golpe daquele ano, teve também o registro da prisão em 7 de abril de 1964, em nota no mesmo jornal (Figura 4).

O golpe militar de abril de 1964 desarticulou um dos momentos mais criativos e efervescentes para a educação crítica e a cultura popular no país, mas o Método Paulo Freire e sua concepção de educação resistiram por muitos anos em projetos na base da sociedade. Fugindo do controle do Estado, espalharam-se não apenas no Brasil, mas também na América Latina, tendo chegado depois a outros continentes. O PNA foi imediatamente extinto após o golpe, e Paulo Freire encarcerado. Os currais eleitorais continuaram elegendo seus políticos conservadores desinteressados na consolidação de um sistema de educação mais abrangente e inclusivo. (HADDAD, 2019, p. 892).

O Diario de Pernambuco dedicava espaços elogiosos a Paulo Freire, mas a partir de sua prisão e do exílio de 1964 a 1979, passa a imprimir outros teores. O jornal inicia um período de publicações contendo acusações dirigias ao educador. Entre elas que o professor fazia uso de dinheiro público e adjetivos como "agitador", "subversivo", "pervertido" e "doutrinador comunista". A abordagem do jornal vai se abrandar somente no final dos anos de 1970, quando a anistia aos exilados e presos políticos passam a ganhar força no Brasil.

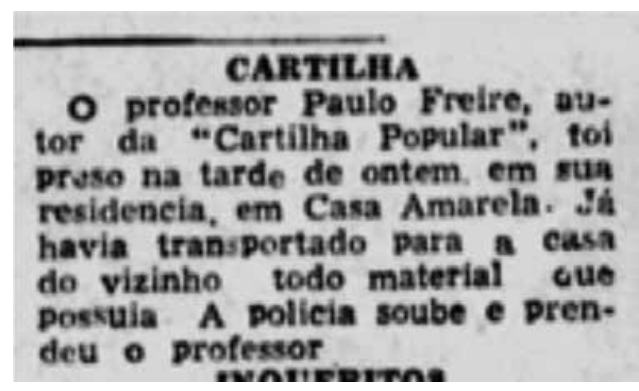

Figura 4 - Nota sobre a prisão de Paulo Freire, Diario de Pernambuco, 8 abr. 1964, p. 7.

7 Disponível em: http://memoria.bn.br/DocReader/DocReader.aspx?bib=029033_14\&pagfis=23235. Acesso em: 20 fev. 2021. 
Na edição de 12 de abril de 1964, na página 4 do "Primeiro Caderno" do Diario de Pernambuco, a coluna "Informativo Econômico" é encerrada com a seguinte frase: "[...] o Movimento de Cultura Popular da fina flor do esquerdismo indígena, doutrinava os camponeses na campanha de 'politização' liderada pelo método Paulo Freire que acobertava”. Em 26 de abril de 1964, na página 2 do "Terceiro Caderno", o mesmo jornal mencionava que o governador Miguel Arraes, destituído do cargo pelo golpe de Estado de 1964, tinha como "cartilha política" o método Paulo Freire. E que "[...] a origem era o decalque rumbeiro do fidelismo de fora para dentro, e o desarnar não era instruir, mas o abecedário do desenhar o nome o garatujo do chamegão no voto para a consolidação 'democrática' da ciganada cosmopolita tendo vez na direção da Pátria."

Um mês após a prisão de Paulo Freire, em 7 de maio de 1964, uma nota na página 6 do Diario de Pernambuco, no "Segundo Caderno" do jornal, relata: "Aproveitaríamos o Método Paulo Freire, cujo inconveniente era a cartilha destinada a doutrinação comunista". Ainda como amostra do tratamento dispensado ao professor Paulo Freire, a coluna "Informativo Econômico" do periódico resumia, no segundo parágrafo da edição de 14 de julho de 1964, na página 4, os acontecimentos daquele ano:

A Revolução do dia 31 de março foi feita contra um estado de coisas no plano político, social e econômico. Foi feita contra a subversão, contra a corrupção e contra o comunismo. Em Pernambuco extinguiu o Movimento de Cultura Popular; acabou com os programas da Rádio Universidade de Recife, de sentido político doutrinário marxista-leninista; fez desaparecer o método Paulo Freire; prendeu políticos e elementos comprometidos; eliminou as Ligas Camponesas; desmanchou as lideranças camponesas dos sindicatos rurais, engajadas na subversão e na desordem; interveio nos Sindicatos operários urbanos. Certíssimo. ${ }^{8}$

Durante o exílio de Freire, o Diario de Pernambuco prosseguia noticiando as acusações de subversão dirigidas ao educador. $\mathrm{Na}$ edição de 10 de janeiro de 1965, na página 4, a coluna "Rural", assinada por José Belém Wanderley trazia entre o texto do primeiro parágrafo a seguinte referência ao educador:

O abecê do lavrador a liderança canhota não ensinava a ninguém. $\mathrm{O}$ aprendizado todo era o sistema revolucionário da cartilha do método Paulo Freire; do obtuso Movimento de Cultura Popular. Os Jecas e os Jocas, eram chupados e abanados pelos morcegos do regime de importação; duvidoso e deteriorado, na sua origem do jargão afogueado. ${ }^{9}$

A edição do Diario de Pernambuco, de 12 de junho de 1965, inicia a página 2 do "Segundo Caderno" com um artigo acusatório a Paulo Freire, em denúncia contra

8 Disponível em: http://memoria.bn.br/DocReader/DocReader.aspx?bib=029033_14\&Pesq=\%22Paulo\%20Freire\%22\&pagfis=30323. Acesso em: 20 jan. 2021.

9 Disponivel em: http://memoria.bn.br/DocReader/DocReader.aspx?bib=029033_14\&Pesq=\%22Paulo\%20Freire\%22\&pagfis=33771. Acesso em: 20 jan. 2021. 
indiciados num inquérito sobre a Universidade de Recife:

Como principal denunciado figura o ex-diretor do Serviço de Extensão Cultural, e do Programa Nacional de Alfabetização de Adultos, Paulo Freire, "cerne intelectual da subversão na Universidade", segundo o promotor Fialho de Oliveira. Diz o representante do Ministério Público, na sua denúncia que o Sr. Paulo Freire com colaboração da Rádio Universidade, fazia do Serviço de Extensão Cultural da Universidade de Recife e do Programa Nacional de Alfabetização de Adultos meios para a propaganda de ideologias exóticas e contrárias à ordem política e social estabelecida pela Constituição Federal. O Sr. Paulo Freire é acusado também pelo promotor Fialho de Oliveira, de lançar mão "despudoradamente dos dinheiros públicos". ${ }^{10}$

As publicações dedicadas a Paulo Freire, com elogios ou não, documentaram o incômodo que ele causava às classes dominantes em razão das desigualdades, das contradições e da ausência de ética. As referências do presente artigo revelam a importância do educador e o quadro político do Brasil enquanto ele viveu. Ao resgatá-lo, recorrendo ao Diario de Pernambuco, reconstituem-se momentos que abalaram a sociedade brasileira e a luta do educador pela educação, ética, inclusão e contra a alienação. A ética, as ideias, os ideais e a coragem de Freire o levaram à prisão. Sobre a detenção, ele chegou a declarar que sentiu muito medo relembrando um dos momentos em cárcere:

[...] percebi que se não conseguisse controlar meu medo, ele me destruiria. Para controlá-lo, estabeleci uma relação entre minha experiência individual e o momento político maior no qual estava. Essa comparação entre minha situação e os problemas do país me permitiu um certo distanciamento. (FREIRE; SHOR, 1986, p. 43).

Uma importante referência desse e de outros momentos de Freire consta do documentário radiofônico intitulado Paulo Freire, o andarilho da utopia. ${ }^{11}$ No trabalho, a vida do educador é detalhada entre depoimentos. A direção da produção é do professor e radialista André Barbosa Filho, realizada para a Rádio Nederland da Holanda. Os depoimentos evoluem carregados de sentimentos:

Dentro na cadeia eu refletia: o meu espanto da prisão é um espanto de classe social. Eu encontrei camponeses presos que não tinham espanto nenhum. Nenhum! Porque prisão para ele é óbvio. Faz parte da vida de espoliado que ele é. Eu aprendi muito [...]. Foi esse aprendizado da cadeia que em muito aspecto me preparou para a vida fora do Brasil [...]. O exílio foi uma das grandes oportunidades de aprendizado para mim: as diferenças culturais, por exemplo. A forma de andar. A

10 Disponivel em: http://memoria.bn.br/DocReader/DocReader.aspx?bib=029033_14\&Pesq=\%22Paulo\%20Freire\%22\&pagfis=36580. Acesso em: 20 jan. 2021.

11 Disponível em: http://www.acervo.paulofreire.org:8080/jspui/handle/7891/3279. Acesso em: 25 jan. 2021. 
forma de dizer bom dia. O gosto da comida. Como tudo isso é cultura. E você tem de um lado que cultivar isso, mas do outro você quer superar as exigências maiores da sua cultura. ${ }^{12}$

As expressões de Paulo Freire são simples e pedem reflexões sobre as ações do educador tido como um semeador da ética, da igualdade, da inclusão, da liberdade e da esperança. $O$ pensar de Freire sobre a capacidade humana era uma ação crônica:

O homem e somente o homem é capaz [...] de separar as órbitas existenciais diferentes, de distinguir 'ser' do 'não ser'; de travar relações incorpóreas. $\mathrm{Na}$ capacidade de discernir estará a raiz da consciência de sua temporalidade, obtida precisamente quando atravessando o tempo, de certa forma até então unidimensional, alcança o ontem, reconhece o hoje e descobre o amanhã. (FREIRE, 1983, p. 63).

O retorno de Paulo Freire ao Brasil, em 1979, tem como primeiro destino São Paulo, em 7 de agosto de 1979. Depois, numa quinta-feira, dia 29 de agosto daquele ano, ele desembarca em Recife, ao lado da mulher Elza e de dois filhos. No aeroporto de Guararapes, uma multidão formada por duas mil pessoas aguardava o "andarilho da utopia”. Eram familiares, amigos, intelectuais e admiradores, com faixas e cartazes para homenageá-lo. Segundo o Diario de Pernambuco daquela data, Freire estava "felicíssimo, quase aos prantos, abraçava homens que deixou crianças, velhos que viu na flor da idade e perguntava por amigos que soube terem morrido". A foto estampada na primeira página do jornal imortalizava aquele momento de alegria e o texto resgatava os elogios a Paulo Freire.

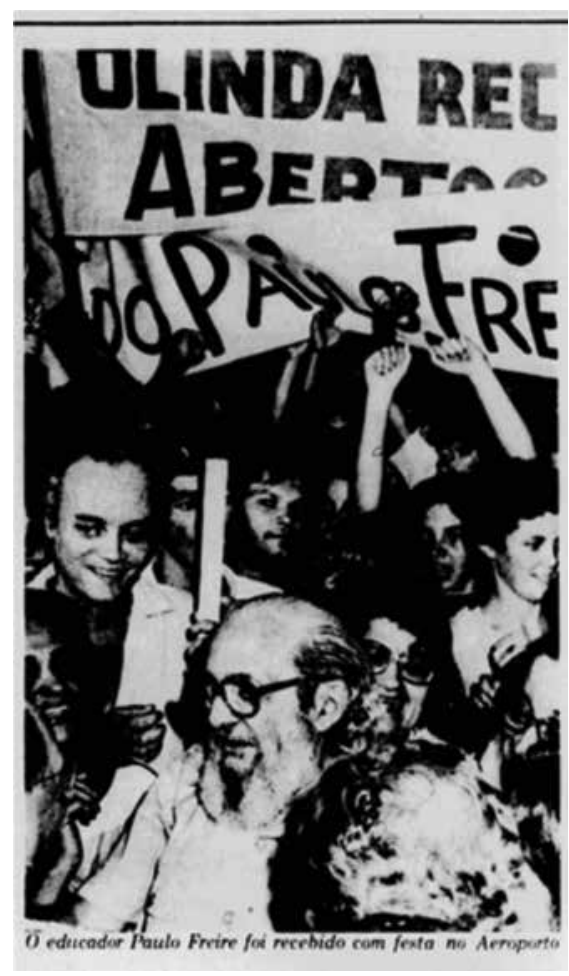

Figura 5 - Foto de Paulo Freire na capa do jornal Diario de Pernambuco, quinta-feira, 30 ago. 1979, quando retorna para Recife, após o exílio iniciado em 1964.

Em 16 de dezembro de 2019, os meios de comunicação do Brasil e do exterior destacavam a fala do presidente da República Jair Messias Bolsonaro, por ele ter chamado o Patrono da Educação Brasileira de "energúmeno". A ofensa ocorreu quando o chefe do Executivo Federal defendeu a

12 Disponível em: https://www.cenpec.org.br/noticias/paulo-freire-o-patrono-legitimo-da-educacao-brasileira. Acesso em: 20 fev. 2021. 
decisão do Ministério da Educação de cancelar o vínculo da TV Escola com a pasta, encerrando o contrato com a Associação de Comunicação Educativa Roquette-Pinto. Na ocasião, o presidente declarou: "Tem muito formado aqui em cima dessa filosofia do Paulo Freire da vida, esse energúmeno aqui que foi ídolo da esquerda". ${ }^{13}$ A reação da viúva de Paulo Freire, Ana Maria Araújo Freire, foi imediata. Na época, aos 86 de idade, afirmou: "Paulo está lá sossegado no lugar dele. Está lá no céu. Bolsonaro é um homem sem nenhum pudor, sem nenhum caráter, sem nenhuma autocensura [...]". Outras manifestações contra a expressão de Bolsonaro se espalharam pelo Brasil e no exterior. Entre elas, a do Senado, que aprovou um requerimento para a realização de uma sessão solene em homenagem a Paulo Freire, ocorrida em maio de 2020.

\section{Considerações finais}

Paulo Freire ultrapassou fronteiras em virtude do método de alfabetização que desenvolveu e pelas ideias e ideais que defendeu. Espontâneo nas falas e nos textos, não negou o medo na prisão, nem a insegurança em terras estrangeiras durante o exílio. Buscou coragem com parceiros de cárcere e expatriados. Via o país de longe e com esperanças. Sobreviveu pelas raízes pernambucanas e pela indignação iniciada frente à pobreza testemunhada e sentida na infância e na juventude. Percebia ali a importância da educação e da ética sobre a ausência de uma política que transformasse a situação da miséria e alienação.

As consultas ao Diario de Pernambuco, jornal da terra de Freire, possibilitaram resgates e interpretações importantes, sobretudo diante das alterações editoriais que o periódico sofreu com as modificações do sistema político brasileiro, tendo fases de promoção e outras de ofensas e acusações contra o educador. Como ocorreu em outros inúmeros jornais e revistas, além de rádios e televisões, todos guardam preciosos depoimentos do professor. Num especial da TV Brasil, no programa De Lá Pra Cá, de 30 de novembro de 2012, ${ }^{14}$ é reproduzido o seguinte depoimento de Freire: "Nunca me senti pior do que ninguém porque sou brasileiro. Eu tenho uma alegria especial por ser brasileiro. Não um orgulho maluco, porque seria inclusive burrice, mas um gosto de falar esse português nordestino". Dessa forma Paulo Freire valorizava o Brasil e vivia a utopia da igualdade.

\section{Referências bibliográficas}

BARBOSA, Filho André. Paulo Freire, o andarilho da utopia. Holanda: Rádio Nederland, 1998. http://www.acervo.paulofreire.org:8080/jspui/handle/7891/3279.

BEISIEGEL, Celso de Rui. Paulo Freire. Recife: Fundação Joaquim Nabuco. Editora Massangana, 2010. 128 p.

13 Disponível em: https://www.correiobraziliense.com.br/app/noticia/eu-estudante/ensino_educacaobasica/2019/12/16/interna-educacaobasica-2019,814436/bolsonaro-diz-que-tv-escola-deseduca-chama-paulo-freire-de-energumeno.shtml. Acesso em: 20 fev. 2021.

14 Disponível em: https://www.youtube.com/watch?v=qGiDAa91UFg. Acesso em: 4 fev. 2021. 
BORTONI-RICARDO, Maris Stella; SILVA, Guia da Maria; CAXANGÁ, Rosário do Maria; LINS Vieira Marli. Raízes sociolingüísticas do analfabetismo no Brasil. São Paulo: Acolhendo a alfabetização nos países de língua portuguesa - Revista eletrônica. 2008. 233 p.

CORREA, Godinho Viviane Michelle. Golpe Militar de 1964. Infoescola, navegando e aprendendo: https://www.infoescola.com/; https://www.infoescola.com/historia/ golpe-militar-de-1964/

DE LÁ PRA CÁ. TV Brasil, 30 nov. 2012. Disponível em: https://www.youtube. com/watch? $=q G i D A a 91 U F g$. Acesso em: 20 fev. 2021

DIARIO DE PERNAMBUCO. Recife, edições de: 14 abr. 1963, p. 11; 25 abr. 1963 , p. 9; 29 maio 1963, p. 5; 21 junho 1963, capa; 23 jun. 1963, p. 8; 8 abr. 1964, p. 7; 30 ago. 1979, capa; 10 jan. 1965, p. 04.

FREIRE, Paulo. Conscientização: teoria e prática da libertação - uma introdução ao pensamento de Paulo Freire. 4. ed. São Paulo: Moraes, 1980. 102 p.

FREIRE, Paulo. Ação cultural para a liberdade e outros escritos. Rio de Janeiro: Paz e Terra, 1982. 149 p.

FREIRE, Paulo; SHOR, Ira. Medo e ousadia o cotidiano do professor. Rio de Janeiro: Paz e Terra, 1986. 116 p.

FREIRE, Paulo. Pedagogia da autonomia. Rio de Janeiro: Paz e Terra, 1996. 92 p.

FREIRE, Paulo. Pedagogia do oprimido. Rio de Janeiro: Paz e Terra, 2001. 184 p.

FREIRE, Paulo. Educação como prática da liberdade. 31. ed. Rio de Janeiro: Paz e Terra, 2008. $158 \mathrm{p}$.

HADDAD, Sérgio. O educador, perfil de Paulo Freire. São Paulo: Todavia, 2019. $256 \mathrm{p}$.

LIMA, Venício Artur de. Comunicação e cultura: as ideias de Paulo Freire. Rio de Janeiro: Paz e Terra, 1981. 167 p.

Data do recebimento: $30 / 03 / 2021$

Data do aceite: $15 / 05 / 2021$

Dados do autor:

\section{Pedro Serico Vaz Filho}

Currículo Lattes: http://lattes.cnpq.br/2146332816517256

Pós-doutor pela Escola de Comunicações e Artes da Universidade de São Paulo, CJE-ECA/USP; doutor em Comunicação Social pela Universidade Metodista de São Paulo; mestre em Comunicação pela Faculdade Cásper Líbero; pós-graduado em Teoria e Técnicas da Comunicação pela Faculdade Cásper Líbero; bacharel em Comunicação Social - habilitação em Jornalismo, pela FIAM, Faculdades Integradas Alcântara Machado. Atuou como docente na Universidade São Marcos (SP); Centro Universitário Sant'Anna - UniSant'Anna; Faculdade Cásper Líbero (SP); Universidade Anhembi Morumbi e Escola de Comunicações e Artes da USP (nesta, como docente palestrante). 